Report No.: Y/DZ-2284

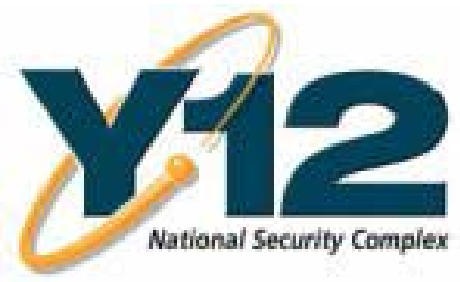

\title{
X-RAY COMPUTED TOMOGRAPHY ON A CELLULAR POLYSILOXANE UNDER COMPRESSION
}

\author{
R. A. Smith \\ M. J. Paulus \\ J. M. Branning \\ P. J. Phillips
}

Development Division

December 8, 2000

MANAGED BY

BWXT, Y-12, L.L.C.

FOR THE UNITED STATES

DEPARTMENT OF ENERGY

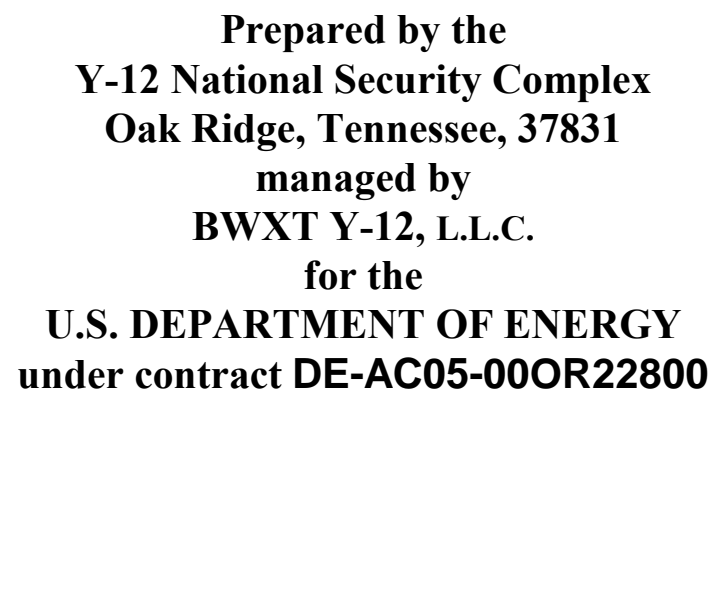




DISCLAIMER
This report was prepared as an account of work
sponsored by an agency of the United States
government. Neither the United States Government nor
any agency thereof, nor any of their employees, makes
any warranty, express or implied, or assumes any legal
liability or responsibility for the accuracy,
completeness, or usefulness of any information,
apparatus, product, or process disclosed, or represents
that its use would not infringe privately owned rights.
Reference herein to any specific commercial product,
process or service by trade name, trademarks,
manufacturer, or otherwise, does not necessarily
constitute or imply its endorsement, recommendation,
or favoring by the United states Government or any
agency thereof. The views and opinions of authors
expressed herein do not necessarily state or reflect
those of the United States Government or any agency
thereof.




\title{
X-RAY COMPUTED TOMOGRAPHY ON A CELLULAR POLYSILOXANE UNDER COMPRESSION
}

\author{
Rosanne A. Smith \\ BWXT Y-12, L.L.C., USA \\ Y-12 National Security Complex \\ Oak Ridge, TN 37831-8094 \\ Michael J. Paulus \\ Oak Ridge National Laboratory, USA \\ Oak Ridge, TN 37831-6006 \\ John M. Branning \\ Purdue University, USA \\ West Lafayette, IN 47906 \\ Paul J. Phillips \\ University of Tennessee, Knoxville, USA \\ Knoxville, TN 37966-2200
}

\begin{abstract}
X-ray tomographic images were collected for polydimethylsiloxane (PDMS) foam material under various levels of compression. The goal was to implement a systematic analysis method of correlating some aspect of these images to the cell morphology in order to enhance understanding of the material characteristics. X-ray attenuation of the cellular PDMS was clearly observed to increase with the specimen density as the foam material was mechanically compressed. The stochastic data derived from the digital images was used to calculate macroscopic mechanical properties at each foam compression.
\end{abstract}

KEYWORDS: open cell, cellular, polysiloxane, foam, x-ray tomography, compressive modulus 


\section{INTRODUCTION}

The permeation characteristics of a polymer foam are being studied, for determination of gas permeation constants and tortuosity changes as the polymer undergoes compression. The cell geometry affects the responses of the foam when in use under compressive loads, and also gas permeation properties. A knowledge of foam variables, which include density, porosity, cell geometry, and gas phase composition, enable one to model the material and its properties. The current study investigated x-ray tomography as a method for obtaining visual images of the polymer at different stages of compression. It then applied the interaction of soft x-ray photons (20 keV) with the PDMS electronic structure to quantify foam features. This unusual polymer comprises $\mathrm{Si}, \mathrm{O}, \mathrm{C}$, and $\mathrm{H}$ atoms, which have mass attenuation coefficients that render good contrast, and therefore a great deal of information. Amorphous carbon-based polymers are relatively transparent to this mode of x-ray examination and require crystalline structure in order for x-ray diffraction patterns to be discerned. The cellular PDMS in this study has an amorphous microstructure and a foam macrostructure. Therefore x-rays which scatter from the solid phase of this material will be detected in proportion to the mass of polymer present, in contrast to void space. Furthermore, the elemental attenuation of x-rays by the polymer matrix provides quantitative information about the foam content and compression.

\section{MATERIAL}

The specimen was a cellular poly(dimethyl siloxane) or PDMS. The foam morphology is opencell with a nominal density of $0.615 \mathrm{~g} / \mathrm{cm}^{3}$. Polydimethyl siloxanes $\left(\left[-\mathrm{Si}\left(\mathrm{CH}_{3}\right)_{2} \mathrm{O}-\right]_{\mathrm{n}}\right)$ are substituted siloxane chains, with the formula: 


$$
\left[\underset{\mathrm{CH}_{3}}{-\mathrm{SH}_{3}}\right]_{\mathrm{n}}
$$

This polysiloxane type contains methyl groups, but even with more bulky R groups, the siloxane chain remains relatively flexible. This dynamic flexibility arises from the relatively long $\mathrm{Si}-\mathrm{O}$

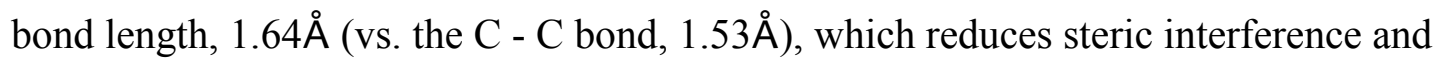
"intramolecular congestion." This polymer contains silica filler and is crosslinked during the foaming process.

The rectangular specimen, of dimensions 1.5 -inch length, 0.5 -inch width, and 0.3 -inch height, was cut from a 0.3 -inch thickness foam slab. The specimen was held in an acrylic holder of internal dimensions 1.5 inch (length) x 0.5 inch (width) x 0.5 inch (height), and 0.1 -inch wall thickness. Shims of this same material were used to compress the specimen, having various thicknesses required in order to obtain compressions of $10 \%, 20 \%, 30 \%, 40 \%, 50 \%$, and $60 \%$. Three-dimensional images were built at each of these compressive states by obtaining twodimensional slices of $70 \mathrm{~nm}$ resolution. For each compressive level, some 200 data slices were collected from each of the $\mathrm{x}, \mathrm{y}$, and $\mathrm{z}$ planes, thus requiring 600 sets of data for each compression (4200 total sets of 2-D data). The PDMS foam cells were approximately $0.065-0.070 \mathrm{~mm}$ in diameter with open faces, as seen in the optical micrograph (Figure 1). This material is easily compressed with the cell walls folding into one another as force is applied.

Unixial compression is affected by insertion of increasingly wide shims into the sample holder, thereby decreasing the length of the holder, up to $60 \%$ in $10 \%$ increments. Even with this 
decrease in volume, the specimen volume does not decrease proportionally, but only by 45 percent at the maximum compression of $60 \%$. The decrease in material porosity is determined by calculating the new density at each compression, since

$$
\rho_{\text {foam }}=\mathrm{m}_{\text {polymer }} / \mathrm{V}
$$

where the polymer mass $\left(\mathrm{m}_{\text {polymer }}\right)$ is constant, and a new polymer foam volume $\mathrm{V}$ can be calculated for each compressive state. Table I is a summary of the specimen dimensions, volume and porosity, where the porosity is a dimension less quantity defined as the ratio of void volume to the porous specimen volume. $[1,4]$, where

$$
\frac{V_{\text {specimen }}-V_{\text {polymer }}}{V_{\text {specimen }}}=\frac{V_{\text {void }}}{V_{\text {specimen }}}=\text { Porosity . }
$$

\section{EXPERIMENTAL}

Computed x-ray tomography is a method used in the fields of medicine, biology, and geology, due to its noninvasive and nondestructive capability to obtain two-dimensional and threedimensional images of complex structures. Three-dimensional x-ray tomographic equipment comprising the Oak Ridge National Laboratory (ORNL) Microcomputer Assisted Tomography (MicroCAT) system was used to examine the foam structure. The MicroCAT, developed for imaging mice and other biological entities, used a $40 \mathrm{kVp} \mathrm{x}$-ray source from a $75 \mathrm{~W}$ tungsten anode source, and a MedOptics Phospor screen/CCD array detector. The x-ray energy has been experimentally determined to be $20 \mathrm{keV}$ as filtered with an aluminum sheet of $0.5 \mathrm{~mm}$ thickness. The system was controlled using Windows NT.

This method reconstructs $\mathrm{x}$-ray detector signals from various paths through the specimen, 
comparing them to the initial beam intensity. For each incident beam $\mathrm{I}_{0}$, passing through a sample of thickness $\mathrm{x}$, an outgoing beam $\mathrm{I}_{1}$ has been attenuated by the quantity $\mu \mathrm{x}$, where $\mu$ is the linear attenuation coefficient, or energy absorption amount for the atoms contained in that thin layer $\Delta \mathrm{x}$. Integrating over the entire $\mathrm{x}$ distance, each path generates an unknown value of $\mu$ :

$$
\frac{\mathrm{I}_{\mathrm{o}}}{\mathrm{I}_{1}}=\exp \left\{-\int_{\mathrm{x}} \mu(\mathrm{x}) \mathrm{dx}\right\},
$$

The detectors are located in a circular array around the specimen; using rotation and translational motion along a $\mathrm{z}$-axis, each point in the specimen is $\mathrm{x}$-rayed across several paths. A large matrix of intensity equations is then solved for unknown values of $\mu$, using a reconstruction algorithm. This provides linear attenuation coefficient values which correspond with specific elements and their spatial locations in the specimen. Consecutive slices of $35 \mu \mathrm{m}$ resolution slices are collected, resulting in a 3-D image which maps the set of x-ray linear coefficients.

\title{
DATA COLLECTION AND ANALYSIS
}

\author{
Grayscale Images
}

Scion Image software has the capability to generate a profile plot of the grayscale intensity of the image across a plane of the specimen. It was noted that the overall intensity range correlates with the degree of compression; for example, the uncompressed specimen of void volume 0.483 has an average 200 points between the highest and lowest level of brightness of the image. This can be compared with the most compressed foam (60\%), which has a void volume of 0.063 . In this case, the difference in brightness range is only about 60, with the minimum brightness never going below 98. This indicates polymer matrix density across the entire image, whereas the intensity of the uncompressed specimen reaches zero at several points where there is no matrix 
material, hence locate an open void where there is no attenuation.

The foam characterization methods developed by Delesse [7] and later carried forward by Rhodes and Khaykin [8] use stereology to project two-dimensional feature information into a three-dimensional space. As described earlier, one can imagine a cube cut from the specimen and a grid superimposed upon a bisecting plane (see Figure 2). The area bounded by "irregular" volume domains is the 2-D projection of the 3 -D void volume. In a similar fashion, onedimensional line sections are found to be proportional to the volume fraction of features. In this case, the fraction of line located on the void can be shown to estimate the area and volume of the void phase where:

$$
\frac{\mathrm{L}_{\mathrm{i}}}{\mathrm{L}}=\frac{\mathrm{A}_{\mathrm{i}}}{\mathrm{A}}=\frac{\mathrm{V}_{\mathrm{i}}}{\mathrm{V}}
$$

and $\mathrm{L}_{\mathrm{i}}, \mathrm{A}_{\mathrm{i}}$, and $\mathrm{V}_{\mathrm{i}}$ represent the lineal fraction, the areal fraction, and the volume fraction of the void space, respectively [7]. This correlation carries even further to $\mathrm{P}_{\mathrm{i}}$, the fraction of points located in phase $\mathrm{i}$, as measured on a grid of points $\mathrm{P}$.

In this study, the grayscale indication quantifies the relative area of voids across a selected specimen cross-sectional area. While image resolution is not small enough to characterize single cells or walls, a stochastic approach will be taken by correlating the grayscale to the CT numbers (see section II). These are the raw data collected by the detector, and are a direct measure of the $\mathrm{x}$-ray interaction with the material. From a stochastic standpoint, this is the probability of finding polymer material at a certain location in three-dimensional space. 


\section{CT Numbers}

By converting the grayscale values to CT numbers, quantification of the x-ray interaction with the specimen can be achieved. The CT number, an accepted standard in biological applications, is reported in Hounsfield Units (HU) and is an indicator of the specimen's electron density. One of the specific set of CT numbers has a scale from $-1000 \mathrm{HU}$ for air to $+1000 \mathrm{HU}$ for bone, with water equal to zero [10]. The number is based upon the linear x-ray coefficient value, $\mu$, of the specimen as compared to that of water, $\mu_{\mathrm{H} 2 \mathrm{O}}$ :

$$
\text { CT number }=\left(\frac{\mu-\mu_{\mathrm{H} 2 \mathrm{O}}}{\mu_{\mathrm{H} 2 \mathrm{O}}}\right) \times 1000
$$

where $\mu$ is the linear $\mathrm{x}$-ray attenuation coefficient of the material as a function of $\mathrm{x}$-ray energy. For this work, the raw attenuation data was initially converted to CT numbers. At an x-ray energy of $20 \mathrm{keV}, \mu_{\mathrm{H} 2 \mathrm{O}}=0.8096 \mathrm{~cm}^{-1}$, whereas at $22.5 \mathrm{keV}, \mu_{\mathrm{H} 2 \mathrm{O}}=0.7 \mathrm{~cm}^{-1}$. The need for the latter calculation will be explained in the next section.

CT numbers obtained from specimen center slices of area 64 pixel x 64 pixel were plotted as a function of pixel number across the width of the specimen. Figure 3 shows plots obtained for zero percent, $30 \%$, and $60 \%$ compressions matched to a cross-sectional image for each. The fluctuation in CT number, as a result of void depth, matches to that of the grayscale data. The range between high and low $\mathrm{CT}$ numbers is large, in the case of the uncompressed sample; the average CT number is smaller in this situation than at any other compressive state. This indicates that the x-ray interaction with silicon atoms is at its minimum since there is less surface area (larger cell void space) available for scattering. Figure 4 shows CT number value averages at each compression. 


\section{X-ray Mass Attenuation Coefficients}

At the highest compression, the CT curve appears to approach a limiting value, which one might assume is the CT number for nonfoam PDMS. In order to determine the limiting value of the CT Number, it is necessary to obtain the mass attenuation coefficient from the literature. From the NIST reference, one can find the $\mu / \rho$ for elemental silicon, oxygen, carbon, and hydrogen at an x-ray energy of $20 \mathrm{keV}$. Based upon the relative masses of each element $\mathrm{i}$ present in the polydimethylsiloxane polymer (which contains $25 \%$ of a silica filler), a nonfoam or resin $\mu / \rho$ value can be obtained:

$$
\frac{\mu}{\rho}=\sum_{\mathrm{i}} \mathrm{W}_{\mathrm{i}}\left(\frac{\mu}{\rho}\right) \mathrm{i} .
$$

One then uses the density value of $1.19 \mathrm{~g} / \mathrm{cm}^{3}$ [2] in order to determine the $\mu$ value for the PDMS nonfoam material. The limiting CT Number is then determined by substitution into Eq. 5 .

Alternatively, the CT data can be transformed into the form more familiar to materials scientists and engineers by using Eq. 3 above to determine $\mu$, then dividing by the specimen density, $\rho$, to obtain the mass attenuation coefficient, $\mu / \rho$. Data was obtained from the National Institute of Standards and Technology web site http://physics.nist.gov/PhysRefData/XrayMassCoef/ where NISTIR 5632 lists elemental x-ray attenuation coefficients for x-ray energies of range $10^{-3}$ to $10^{2}$ $\mathrm{MeV}[6]$.

Based upon calculations of the polydimethylsiloxane specimen constituents, the elemental content is calculated to be $38.5 \mathrm{wt} \% \mathrm{Si}, 28.7 \mathrm{wt} \% \mathrm{O}, 26.6 \mathrm{wt} \% \mathrm{C}$, and $6.2 \mathrm{wt} \% \mathrm{H}$. Using these 
elemental weight fractions, one uses the formula $(\mu / \rho)_{\text {foam }}=w_{S_{i}}(\mu / \rho)_{S_{+}} w_{\circ}(\mu / \rho)_{O}+w_{C}(\mu / \rho)_{C}+$ $\mathrm{W}_{\mathrm{H}}(\mu / \rho)_{\mathrm{H}}$ with the attenuation coefficients for $20 \mathrm{keV}$ photon energy to calculate that $\mu / \rho=2.1$ $\mathrm{cm}^{2} / \mathrm{g}$ for the polymer itself. These numbers assume a homogeneous specimen, such as a polymer resin with no void spaces.

The average experimental CT numbers are converted to $\mathrm{x}$-ray attenuation measurements as expressed in Eq. 3. This data, based upon the $20 \mathrm{keV} x$-ray energy source, is presented in Table 2 , as a function of specimen location and compression. The maximum attenuation coefficient would be attained for the resin form of the polymer; this theoretical value has been included. As one would expect, the increasingly compressed cellular polymer has a $\mu / \rho$ approaching that of the resin.

It was further determined that the absorption of lower energy $\mathrm{x}$-rays by the specimen required recalculation of the average attenuation coefficients. The average mass attenuation coefficients are now extrapolated to a $22.5 \mathrm{keV}$ photon energy, and the results shown as the final column in Table 3, a summary of compression-related foam characteristics.

Figure 5 plots relative density and mass attenuation coefficient behavior as the cellular PDMS is compressed, and porosity of the foam is reduced. Although these features trend in a similar manner, the relative density data (left-hand y-axis) appears to exceed the expected value $\left({ }^{\rho *} / \mathrm{p}=1\right)$ by $10 \%$. The $x$-ray attenuation coefficient (right-hand y-axis) experimentally falls about $8 \%$ short of its calculated value of $1.769 \mathrm{~cm}^{2} / \mathrm{g}$. There are plans to compile $\mathrm{x}$-ray attenuation data from a resin specimen. 


\section{APPLICATION OF DATA TO MECHANICAL PROPERTY DETERMINATIONS}

Polymeric foams offer mechanical advantages, due to their light weight and wide range of properties, particularly their density, modulus, and compressive strength [5]. These attributes are prescribed by the matrix polymer in combination with the cellular geometric structure. Recognizing that the compressions obtained in the current study require a certain loading level, the data obtained was used further in mechanical calculations.

Compression of a foam is described by the polymer modulus, $\mathrm{E}$, foam modulus, $\mathrm{E}_{\mathrm{f}}$, compressive strain, $\varepsilon$, and a dimension less function of strain that describes strut buckling, $\Psi(\varepsilon)$. The compressive stress $\sigma$ is expressed as

$$
\sigma=\mathrm{E}_{\mathrm{f}} \varepsilon \Psi(\varepsilon)
$$

$\mathrm{E}_{\mathrm{f}}$ has a dependency on cellular structure related to $\mathrm{E}$ and to the fraction of polymer, $\varphi$, residing in the foam. (It should be noted that the term $\varphi$ is equivalent to the relative density, $\rho * / \rho$, as described by Gibson and Ashby [5].) For sphere-shaped cells,

$$
\mathrm{E}_{\mathrm{f}}=\frac{\varphi \mathrm{E}}{12}\left(2+7 \varphi+3 \varphi^{2}\right)=\mathrm{CE}
$$

It is appropriate that $\mathrm{E}_{\mathrm{f}}$ approach $\mathrm{E}$ as $\varphi$ goes to 1 . The value of $\mathrm{E}$ for this particular PDMS polymer is given as $275 \mathrm{psi}$ [3] and an empirical value for flexible polyurethane foams will be used allowing a strut buckling factor $\Psi(\varepsilon) \cong \varphi^{0.28}[9]$.

Applying these relationships and above data to the PDMS cellular polymer, Table 4 summarizes 
calculations made in order to obtain the foam modulus, stress, and compressive load at each compression. It would be fruitful to improve the strut buckling factor assumption, as one would expect polydimethylsiloxane to behave differently than flexible polyurethane. Figure 6 shows the result of plotting the compressive stress (load per area) against the compressive strain; only two of the deformation regions described by Gibson and Ashby [5] can be observed in this case, the elastic buckling region and the densification region. The absence of a linear bending region may be due to the stepwise and static nature of these compressions, whereas typical loading tests are dynamic. Another conclusion is that cell wall bending is the primary response to foam loading, with little deformation by cell wall compression. Regardless, the data for each compression agree with their general rule that

$$
\frac{\mathrm{E}_{\mathrm{f}}}{\mathrm{E}} \approx\left(\frac{\rho *}{\rho}\right)^{2}
$$

\section{CONCLUSIONS}

It has been shown that $\mathrm{x}$-ray tomography is a useful nondestructive method for understanding the compressive behavior of a loaded polymer foam. As a general trend, the experimentally obtained x-ray attenuation coefficient could be correlated with the effective density of the polymer foam, $\rho * / \rho$, where $\rho^{*}$ is the density of the original foam, and $\rho$ is the resin (nonfoam) polymer density. 
done during application of the compressive force. The data acquired was used to characterize certain mechanical properties of the cellular polysiloxane material. Further analysis of these results will elicit a better understanding of the cellular structure of this material, even as improved resolution of the MicroCAT brings about higher resolution image data. 


\section{REFERENCES}

1. Bear, J. Dynamics of Fluids in Porous Media. New York: American Elsevier.

2. Cady, W. E., Jessop, E. S., McKinley, B. M. 1982. Property of Cellular Silicone from High Vinyl Silicone Gums as a Function of Porosity. Livermore, CA: LLNL Report UCRL-53366.

3. Chien, A. T., Felter, T., LeMay, J. D., Balooch, M. 2000. J. Mat. Sci., 15, 4:838.

4. De Marsily, G. 1991. "Stochastic Description for Porous Media” in Modeling and Applications of Transport Phenomena in Porous Media. Ed. Bear, J. and Buchlin, J-M. Dordrecht: Kluwer.

5. Gibson, L. J, and Ashby, M. F. 1997. Cellular Solids - Structure and Properties, $2^{\text {nd }}$ Ed. Cambridge: University Press.

6. Hubbell, J. H., Seltzer, S. M. 1996. NISTIR 5632: Tables of X-Ray Mass Attenuation Coefficients and Mass Energy-Absorption Coefficients at website address http://physics.nist.gov/PhysRefData/XrayMassCoef/. Washington, D. C.: National Institute of Standards and Technology.

7. Kampf, G. 1986. Characterization of Plastics by Physical Methods - Experimental Techniques and Practical Applications. Munich-Cincinnati: Hanser Publishers.

8. Rhodes, M. B., Khaykin, B. 1986. Langmuir, 2:643.

9. Rusch, K. C. 1969. J. Appl. Polym. Sci., 13:2297.

10. Website address: http://www.teaching-biomed.man.ac.uk/student_projects/2000/ mmmr7gjw/glossary.htm\#H . 


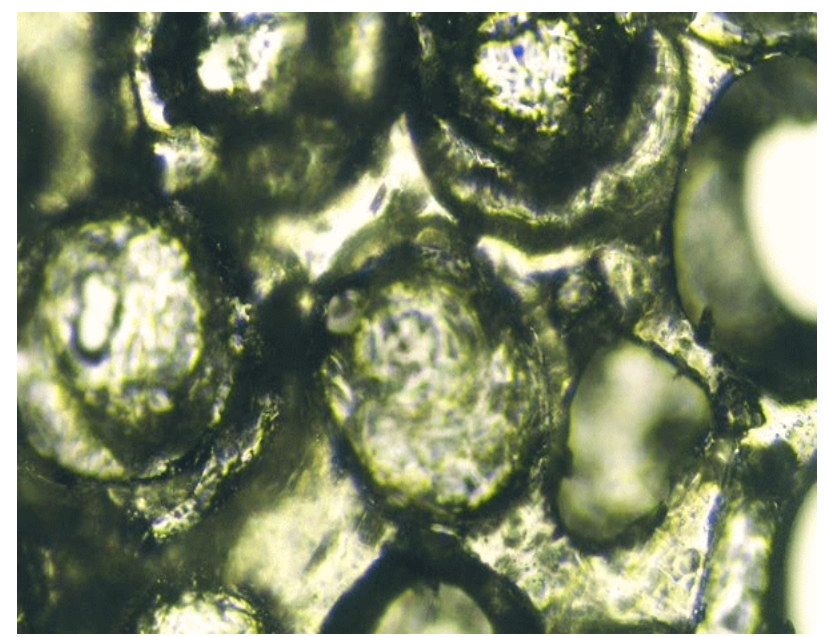

Figure 1. Optical micrograph of cellular polydimethylsiloxane of $0.615 \mathrm{~g} / \mathrm{cm}^{3}$ density $(100 \mathrm{x}$ magnification). 


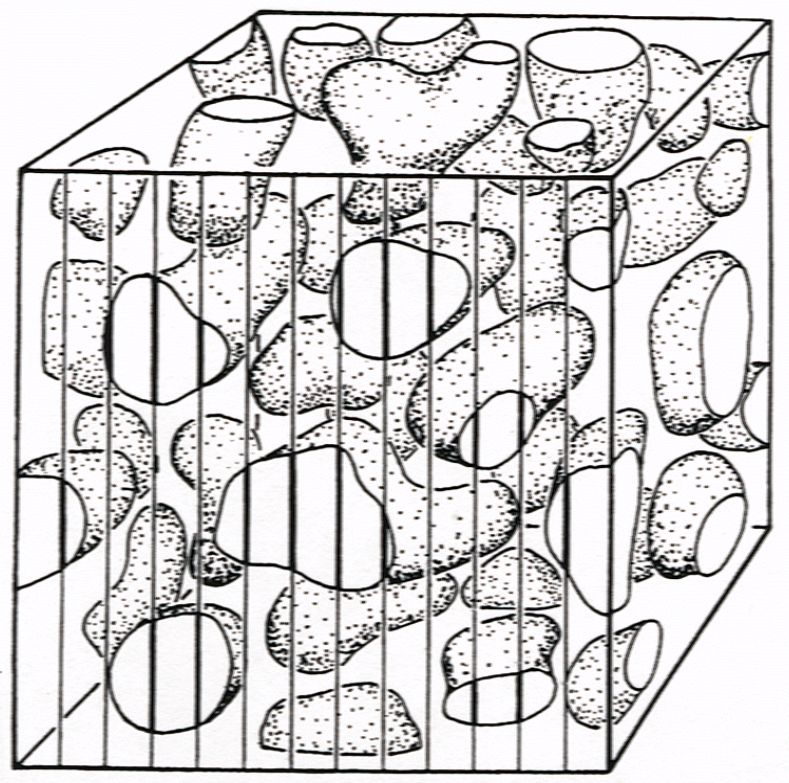

Figure 2. Example volume containing a dispersed void phase, the content of which can be determined by cross-sectional lengths shown (from Kampf). 

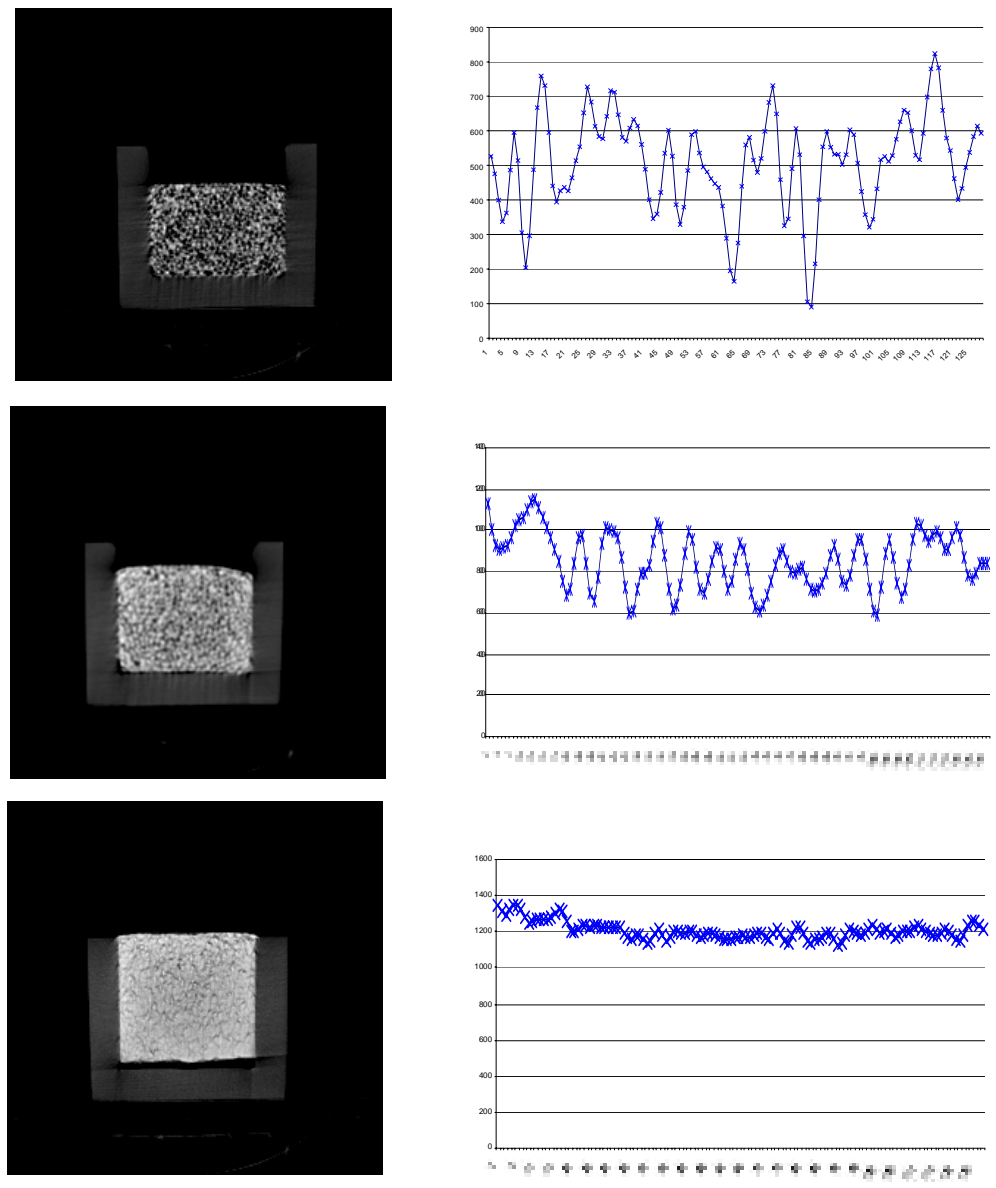

Figure 3. At left: $x$-ray images of $0 \%, 30 \%$, and $60 \%$ compressed foam specimens across midsection. At right: respective grayscale variation plots of average $C T$ number as a function of pixel number. Specimen width of $1.27 \mathrm{~cm}$ equates to 128 pixels. Note that grayscale plots include data for specimen only, and not the specimen holder (seen as a u-shape in the x-ray images). 


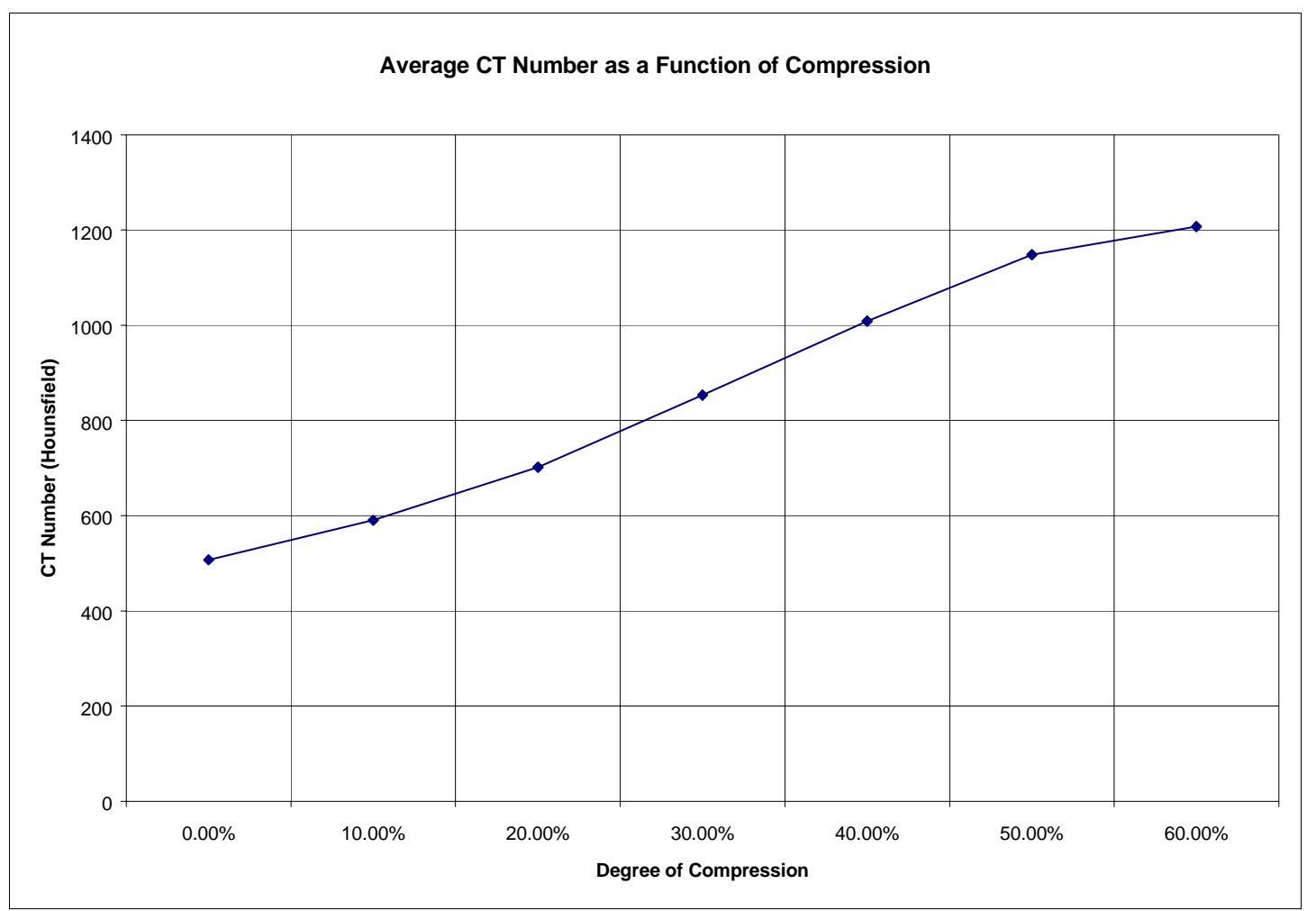

Figure 4. CT Number Average for Center Plane of Specimens 


\section{Relative Density $(\rho * / \rho)$ and Mass Attenuation Coeff. $(\mu / \rho)$ as a function of compression}

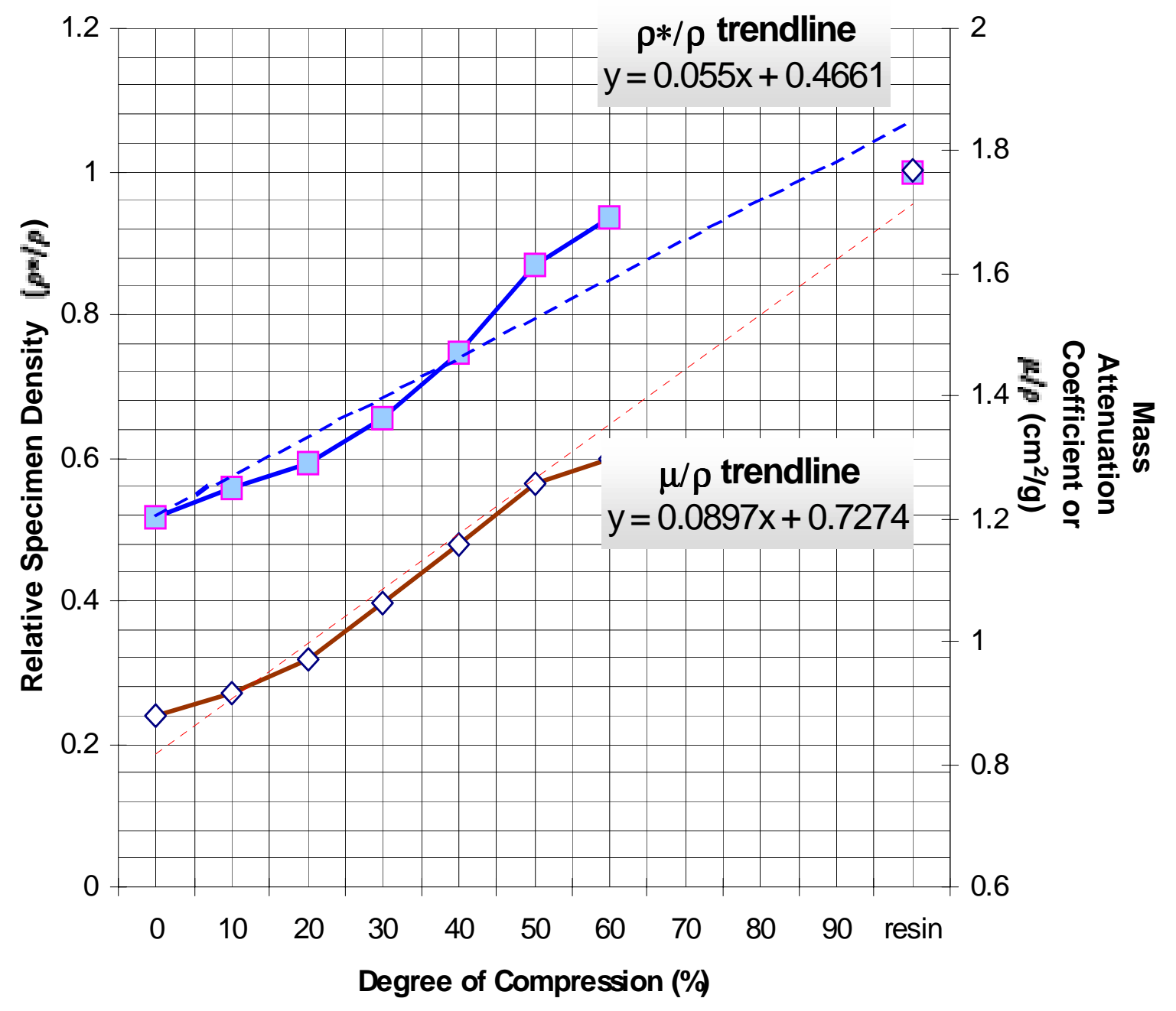

Figure 5. Comparison of relative cellular polymer density and mass attenuation coefficient for 22.5 keV x-rays, as foam is compressed. Straight lines project values for solid polymer as the 100\% compressed foam. 
Compressive stress-strain behavior for $.615 \mathrm{~g} / \mathrm{cm}^{3}$ density polysiloxane open cell foam

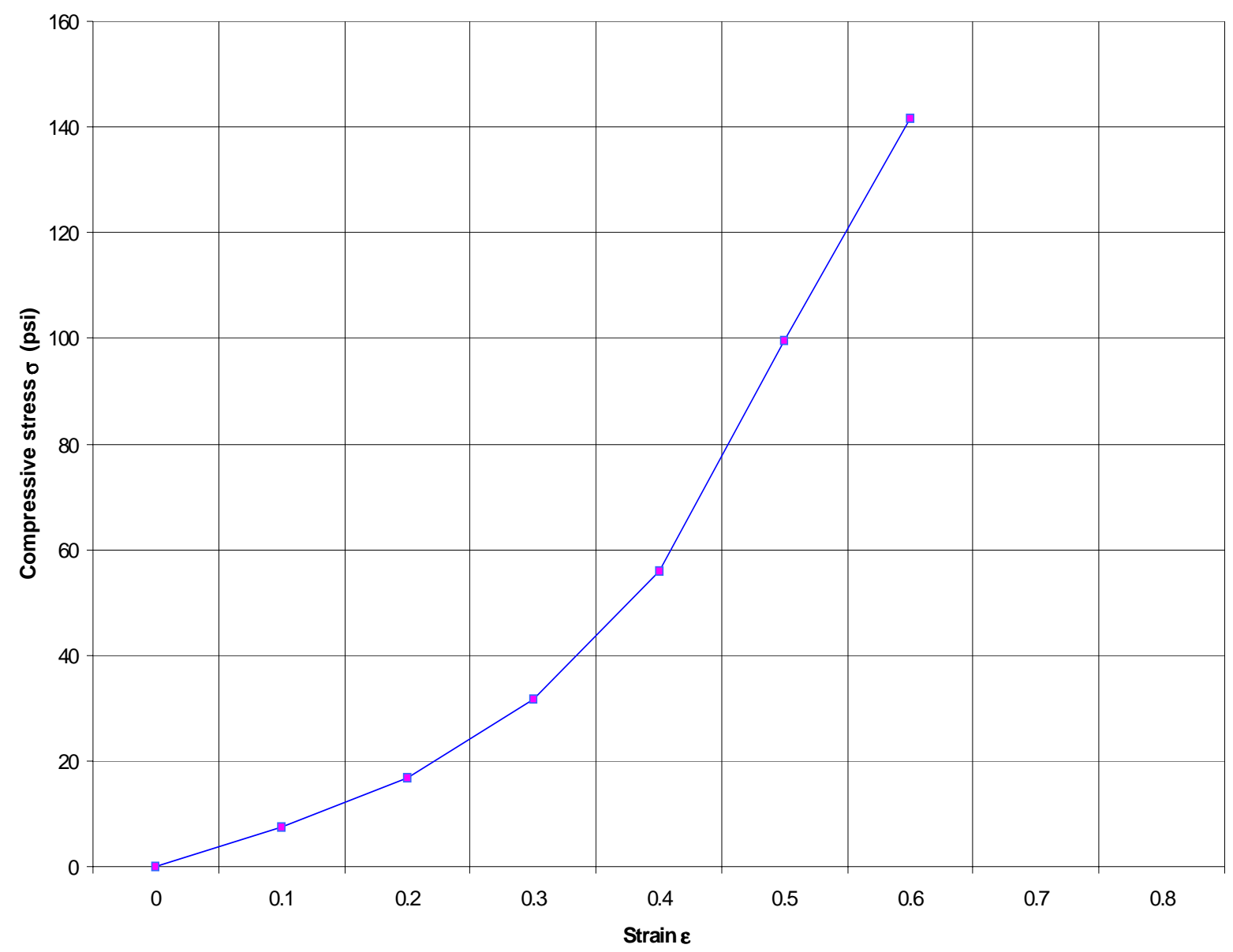

Figure 6. Compressive stress-strain curve for open cell polysiloxane foam of density $0.615 \mathrm{~g} / \mathrm{cm}^{3}$. 
Table 1. Specimen dimensions at uniaxial compressive states.

\begin{tabular}{|c|c|c|c|c|c|c|c|c|c|c|c|c|c|}
\hline \multirow{2}{*}{$\begin{array}{l}\text { Com- } \\
\text { pres- } \\
\text { sion }\end{array}$} & \multicolumn{2}{|c|}{$\begin{array}{c}\text { Shim } \\
\text { Length }\end{array}$} & \multicolumn{2}{|c|}{$\begin{array}{l}\text { Specimen } \\
\text { Length }\end{array}$} & \multicolumn{2}{|c|}{$\begin{array}{l}\text { Specimen } \\
\text { Width }\end{array}$} & \multicolumn{2}{|c|}{$\begin{array}{c}\text { Specimen } \\
\text { Height }\end{array}$} & \multicolumn{2}{|c|}{$\begin{array}{l}\text { Specimen } \\
\text { Volume }\end{array}$} & \multicolumn{2}{|c|}{$\begin{array}{c}\text { Specimen } \\
\text { Density }\end{array}$} & \multirow{2}{*}{$\begin{array}{l}\text { Porosity } \\
\mathbf{V}_{\text {void }} / \\
\mathbf{V}_{\text {specimen }}\end{array}$} \\
\hline & in & $\mathbf{c m}$ & in & cm & in & $\mathbf{c m}$ & in & $\mathbf{c m}$ & in $^{3}$ & $\mathbf{c m}^{3}$ & $\mathrm{lb} / \mathbf{i n}^{3}$ & $\mathrm{~g} / \mathrm{cm}^{3}$ & \\
\hline $0 \%$ & 0 & 0 & 1.50 & 3.81 & 0.5 & 1.27 & .307 & .871 & 0.257 & 4.215 & 0.022 & .615 & 0.483 \\
\hline $10 \%$ & 0.15 & 0.38 & 1.35 & 3.43 & 0.5 & 1.27 & .353 & .897 & 0.238 & 3.906 & 0.024 & .664 & 0.442 \\
\hline $20 \%$ & 0.30 & 0.76 & 1.20 & 3.05 & 0.5 & 1.27 & .375 & .953 & 0.225 & 3.689 & 0.025 & .703 & 0.410 \\
\hline $30 \%$ & 0.45 & 1.14 & 1.05 & 2.67 & 0.5 & 1.27 & .386 & .980 & 0.203 & 3.319 & 0.028 & .781 & 0.344 \\
\hline $40 \%$ & 0.60 & 1.52 & 0.90 & 2.29 & 0.5 & 1.27 & .396 & 1.01 & 0.178 & 2.921 & 0.032 & .887 & 0.254 \\
\hline $50 \%$ & 0.75 & 1.91 & 0.75 & 1.91 & 0.5 & 1.27 & .407 & 1.03 & 0.153 & 2.502 & 0.037 & 1.036 & 0.130 \\
\hline $60 \%$ & 0.90 & 2.29 & 0.60 & 1.52 & 0.5 & 1.27 & .473 & 1.20 & 0.142 & 2.325 & 0.040 & 1.115 & 0.063 \\
\hline
\end{tabular}


Table 2. X-Ray Attenuation Coefficients for Polysiloxane Foam as Calculated from CT Numbers at Compressions Ranging from 0 to $60 \%$, and Locations Along the Specimen Length.

\begin{tabular}{|c|c|c|c|c|c|c|}
\hline \multirow{2}{*}{$\begin{array}{c}\text { Degree of } \\
\text { Compression }\end{array}$} & \multicolumn{5}{|c|}{$\begin{array}{c}\text { Attenuation Coefficients Based on 20 keV X-ray Energy } \\
\text { Along Relative Distances of Compressed Specimen Length }\end{array}$} \\
\cline { 2 - 7 } & $\mathbf{1 0 \%}$ & $\mathbf{2 5 \%}$ & $\mathbf{5 0 \%}$ & $\mathbf{7 5 \%}$ & $\mathbf{9 0 \%}$ & Average Value \\
\hline $0 \%$ & 1.192 & 1.244 & 1.220 & 1.203 & 1.199 & 1.212 \\
\hline $10 \%$ & 1.315 & 1.303 & 1.287 & 1.21 & 1.190 & 1.261 \\
\hline $20 \%$ & 1.272 & 1.323 & 1.377 & 1.378 & 1.337 & 1.338 \\
\hline $30 \%$ & 1.467 & 1.491 & 1.500 & 1.466 & 1.385 & 1.462 \\
\hline $40 \%$ & 1.558 & 1.573 & 1.626 & 1.613 & 1.608 & 1.596 \\
\hline $50 \%$ & 1.730 & 1.740 & 1.739 & 1.730 & 1.722 & 1.732 \\
\hline $60 \%$ & 1.779 & 1.783 & 1.787 & 1.791 & 1.791 & 1.786 \\
\hline Resin $(100 \%)$ & 2.11 & 2.11 & 2.11 & 2.11 & 2.11 & 2.11 \\
\hline
\end{tabular}


Table 3. Data Summary for Polysiloxane Foam as a Function of Compression.

\begin{tabular}{|c|c|c|c|c|}
\hline $\begin{array}{c}\text { Level of } \\
\text { Compression }\end{array}$ & $\begin{array}{c}\text { Foam } \\
\text { Density } \\
\rho *\end{array}$ & Porosity & $\begin{array}{c}\text { Relative } \\
\text { density } \\
\rho * / \rho\end{array}$ & $\begin{array}{c}\text { X-ray Attenuation } \\
\text { Coefficient @ 22keV } \\
\mu / \rho_{\text {ava }}\left(\mathbf{c m}^{2} / \mathbf{g}\right)\end{array}$ \\
\hline $0 \%$ & 0.615 & 0.483 & 0.517 & 0.8807 \\
\hline $10 \%$ & 0.664 & 0.442 & 0.558 & 0.9160 \\
\hline $20 \%$ & 0.703 & 0.410 & 0.591 & 0.9723 \\
\hline $30 \%$ & 0.781 & 0.344 & 0.656 & 1.0622 \\
\hline $40 \%$ & 0.887 & 0.254 & 0.745 & 1.1597 \\
\hline $50 \%$ & 1.036 & 0.130 & 0.871 & 1.2588 \\
\hline $60 \%$ & 1.115 & 0.063 & 0.937 & 1.2974 \\
\hline Resin & $\rho=1.19$ & 0 & 1.000 & 1.769 \\
\hline
\end{tabular}


Table 4. Mechanical Properties of Polysiloxane Foam of $48 \%$ Porosity.

\begin{tabular}{|l|c|c|c|c|c|c|c|}
\hline \multicolumn{1}{|c|}{$\boldsymbol{\varepsilon}_{\mathbf{z}}$} & $\boldsymbol{\varphi}$ or $\boldsymbol{\rho} * / \boldsymbol{\rho}$ & $\mathbf{C}$ & $\mathbf{E}_{\mathbf{f}}(\mathbf{p s i})$ & $\boldsymbol{\Psi}(\boldsymbol{\varepsilon})$ & $\boldsymbol{\sigma}(\mathbf{p s i})$ & $\begin{array}{c}\text { area } \\
\left.\mathbf{i n}^{2}\right)\end{array}$ & $\mathbf{F}(\mathbf{l b})$ \\
\hline 0 & 0.517 & 0.277 & 76.074 & 0.831 & 0.000 & 0.154 & 0.000 \\
\hline 0.1 & 0.558 & 0.318 & 87.468 & 0.849 & 7.429 & 0.177 & 1.311 \\
\hline 0.2 & 0.591 & 0.354 & 97.310 & 0.863 & 16.797 & 0.188 & 3.149 \\
\hline 0.3 & 0.656 & 0.431 & 118.508 & 0.889 & 31.594 & 0.193 & 6.098 \\
\hline 0.4 & 0.745 & 0.551 & 151.609 & 0.921 & 55.845 & 0.198 & 11.057 \\
\hline 0.5 & 0.871 & 0.753 & 207.048 & 0.962 & 99.597 & 0.204 & 20.268 \\
\hline 0.6 & 0.937 & 0.874 & 240.344 & 0.982 & 141.603 & 0.237 & 33.489 \\
\hline
\end{tabular}




\section{List of Figures}

Figure 1. Optical micrograph of cellular polydimethylsiloxane of $0.615 \mathrm{~g} / \mathrm{cm}^{3}$ density $(100 \mathrm{x}$ magnification).

Figure 2. Example volume containing a dispersed void phase, the content of which can be determined by cross-sectional lengths shown (from Kampf).

Figure 3. At left: $x$-ray images of $0 \%, 30 \%$, and $60 \%$ compressed foam specimens across midsection. At right: respective grayscale variation plots of average CT number as a function of pixel number. Specimen width of 1.27 inches equates to 128 pixels . Note that grayscale plots include data for specimen only, and not the specimen holder (seen as a u-shape in the x-ray images).

Figure 4. CT number average for center plane of specimens

Figure 5. Comparison of relative cellular polymer density and mass attenuation coefficient for $22.5 \mathrm{keV} \mathrm{x}$-rays, as foam is compressed. Straight lines project values for solid polymer as the $100 \%$ compressed foam.

Figure 6. Compressive stress-strain curve for open cell polysiloxane foam of density 0.615 $\mathrm{g} / \mathrm{cm}^{3}$.

\section{List of Tables}

Table 1. Specimen dimensions at uniaxial compressive states.

Table 2. X-Ray attenuation coefficients for polysiloxane foam as calculated from CT numbers at compressions ranging from 0 to $60 \%$, and locations along the specimen length.

Table 3. Data summary for polysiloxane foam as a function of compression.

Table 4. Mechanical properties of polysiloxane foam of $48 \%$ porosity. 


\section{Rosanne A. Smith}

Rosanne A. Smith is a staff member in the Development Division of the Lockheed Martin Energy Systems, Inc. Y-12 Plant. She performs research in the area of gas flow, diffusion and permeation through polymeric materials. Her education includes a Bachelor of Science degree in chemistry from Howard University, and Master of Science degrees, in chemistry from the University of California, Irvine, and materials engineering from George Washington University, the latter through the Joint Institute of Aeronautical Sciences at NASA/Langley Research Center.

Rosanne Smith is currently pursuing a Ph.D. from the University of Tennessee at Knoxville in the area of Polymer Engineering. Her current study comprises characteristics of flow through cellular polysiloxane as a function of foam compression and gas pressure.

Ms. Smith has extensive project management experience in the areas of manufacturing, metrology, and assembly engineering. She has also managed training, quality assurance, and human resource functions. 


\section{Michael J. Paulus}

Dr. Michael J. Paulus is a senior member of the research staff at the Oak Ridge National Laboratory and a research assistant professor in the University of Tennessee Department of Electrical Engineering. Dr. Paulus received the B.S. degree in electrical engineering at the University of Tennessee in 1985, the M.S. degree in electrical engineering at the University of Dayton and the Ph.D. in electrical engineering from the University of Tennessee. Prior to joining the Oak Ridge National Laboratory, he served as a senior development engineer with CTI, Inc., a leading manufacturer of positron emission tomography (PET) systems. Before that, he served as a member of the research staff of the Georgia Institute of Technology Microelectronics Center, and as a commissioned officer in the United States Air Force, where he performed basic research in the Air Force Wright Aeronautical Laboratories.

Dr. Paulus' research interests include high-resolution x-ray CT and SPECT instrumentation and software for laboratory animal research, novel semiconductor detector development, analog integrated circuit design, and nuclear spectroscopy. He and his research group are currently developing a first-of-its-kind high-resolution three-dimensional dual-modality microSPECT/CT imaging system.

He has authored more than 60 technical publications and presentations in forums focused on medical imaging, microelectronic design, nuclear physics, and disease research. 


\section{John Branning}

John M Branning, Jr is an undergraduate student in electrical engineering at Purdue University. As an undergraduate he participated in the Cooperative Education Program in conjunction with Oak Ridge National Laboratory, where he served as a junior engineer.

Mr. Branning's research interests include image processing, signal processing, and analog and mixed signal integrated circuit design. He has authored three technical publications in the areas of medical imaging and nuclear physics. 


\section{Paul Phillips}

Dr. Paul Phillips is a Professor in the Department of Materials Science \& Engineering at the University of Tennessee, Knoxville. Having earned his B.S. and Ph.D. in physical chemistry at the University of Liverpool, Professor Phillips' first academic appointment was in the Department of Materials at Queen Mary College, University of London in 1970. In 1975, he became an Assistant Professor of Chemical Engineering at the SUNY Buffalo, moved to the University of Utah in 1977 as an Associate Professor of Materials Science and Engineering, becoming a Professor in 1980 and Associate Chairman in 1982. He joined the University of Tennessee in 1984 and has been Director of Graduate Studies in Polymer Engineering since 1991.

Dr. Phillips' best-known research interests are in the general area of solidification of polymers, and its influence on morphology and properties. His studies consider the combined effects of temperature, pressure, molecular weight and copolymer structure on all aspects of crystallization and annealing. Originally well-known for his basic work on the influence of pressure on crystallization, he is now better known for his studies of regimes in crystallization, particularly on how they can be controlled through the detailed chemical microstructure of the polymer.

Dr. Phillips is the coauthor, with Richard H. Boyd, of the graduate textbook "The Science of Polymer Molecules" published by Cambridge University Press in 1994. He has also written numerous chapters, reviews and research reports and about 170 journal articles and refereed conference papers. In 1984 he was elected a Fellow of the American Physical Society for his work on crystallization. 